\title{
Prisoners and prison staff express increased support for prison smoking bans following implementation across Scotland: results from the Tobacco In Prisons study
}

\section{Helen Sweeting, Evangelia Demou, Ashley Brown and Kate Hunt.}

\section{Helen Sweeting - corresponding author}

MRC/CSO Social \& Public Health Sciences Unit, University of Glasgow, 200 Renfield Street, Glasgow, G2 $3 A X, U K$

helen.sweeting@glasgow.ac.uk

0141-353-7500

\section{Evangelia Demou}

MRC/CSO Social \& Public Health Sciences Unit, University of Glasgow, Glasgow, UK

\section{Ashley Brown}

Institute for Social Marketing and Health, University of Stirling, Stirling, UK

\section{Kate Hunt}

Institute for Social Marketing and Health, University of Stirling, Stirling, UK

- Keywords - tobacco smoking; smoke-free policy; implementation science; opinion

- $\quad$ Word count $=525$

- $\quad$ Reference count $=10$

\section{Acknowledgements (if allowed for letter format)}

We are grateful to the staff and prisoners who completed the surveys, and staff at the Scottish Prison Service and at the two non-Scottish Prison Service-run prisons (HMP Addiewell and HMP Kilmarnock) who assisted with the study. We thank colleagues at the MRC/CSO Social and Public Health Sciences Unit's Public Health Research Facility for help with data collection and management, recognise the contribution of our Tobacco In Prisons study co-investigators to the overall design of the study and particularly acknowledge members of the Scottish Prison Service Research Advisory Group and University of Glasgow College of Social Sciences Ethics Committee for their helpful input throughout this research. 
Prisoners and prison staff express increased support for prison smoking bans following implementation across Scotland: results from the Tobacco in Prisons study

\section{INTRODUCTION}

Several jurisdictions have introduced prison smoking bans, responding to concerns around the health of people in custody (hereafter 'prisoner' for brevity) and staff, legal challenges and maintenance costs ${ }^{12}$. Fears of disorder following bans are often expressed in advance. ${ }^{3-5}$ Although generally unfounded, ${ }^{67}$ such fears may reduce the stakeholder support that is vital for successful implementation. ${ }^{8}$ A complete prisoner smoking ban (staff smoking was already banned) was introduced in all 15 Scottish prisons in November 2018, precipitating no significant incidents. ${ }^{9}$ It has been evaluated by the three-phase Tobacco In Prisons study (TIPS). ${ }^{3410}$ TIPs Phase 1 occurred before the ban's announcement; Phase 2 following the announcement, but before policy implementation (during which rechargeable e-cigarettes became available to prisoners); and Phase 3 following implementation.

This novel analysis uses TIPs data to examine prisoners' and prison staff's opinions about prison smoking bans over the course of implementation.

\section{METHODS}

Prison staff surveys were administered online, with links and reminders circulated to staff contacts in all Scottish prisons for forwarding to all prison staff. Staff surveys were open November-December 2016 (Phase 1); May-July 2018 (Phase 2) and May-July 2019 (Phase 3). Prisoner surveys were via paper questionnaires administered November 2016-April 2017 (Phase 1), June-July 2018 (Phase 2) and June-July 2019 (Phase 3). In all except three prisons in Phase 1, prison staff distributed and collected questionnaires (in sealed envelopes protecting confidentiality), generally during overnight lock-up. Staff and prisoner questionnaires included identical/very similar questions around opinions on smoking bans and e-cigarettes in prisons ${ }^{4}$ (Table 1), smoking, health and socio-demographic characteristics.

We compared opinions of both prisoners and staff across Phases, collapsing categories if necessary so all were binary outcomes and testing for differences via logistic regression analyses, adjusting for sociodemographic variables associated with both Phase and opinions. Simple weights were derived to adjust for varying survey return rates between prisons; unweighted results are presented, since they were virtually identical to weighted data results.

\section{RESULTS}

Table 1 shows the lowest return rates in Phase 3 (18.1\% prisoners, $16.1 \%$ staff), compared with highest returns of $33.8 \%$ (prisoners, Phase 1 ) and $31.4 \%$ (staff, Phase 2 ). 
Opinions shifted over time in both groups, although more clearly among staff, with differences between Phases 1 and 3 and, for several items, between Phases 1 and 2 and/or 2 and 3. Initial support for prison smoking bans was higher among staff (see $\left.{ }^{4}\right)$; support increased in anticipation of/following the ban among both prisoners and staff. Importantly, both groups displayed large decreases in the proportions agreeing that prison smoking bans 'cause a lot of trouble' and 'are hard to enforce', particularly: between Phases 2 and 3; and among staff (among whom concerns that bans 'cause a lot of trouble' had increased between Phases 1 (pre-announcement) and 2 (lead-up to ban)). Staff support for prisoner e-cigarette use increased in anticipation of the ban, remaining stable following its implementation.

\section{CONCLUSION}

There were notable opinion changes in both groups in the study period. We acknowledge possible sample bias, but suggest policy-makers should be encouraged by these findings from Scotland which suggest support for prison smoking bans increases among prison staff and prisoners, following largely trouble-free implementation of such bans.

\section{REFERENCES}

1. de Andrade D, Kinner S. Systematic review of health and behavioural outcomes of smoking cessation interventions in prisons. Tobacco Control 2016;Published Online First: 18 October 2016. doi: 10.1136/tobaccocontrol-2016-053297

2. Spaulding A, Eldridge G, Chico C, et al. Smoking in Correctional Settings Worldwide: Prevalence, Bans, and Interventions. Epidemiologic Reviews 2018;40:82-95.

3. Brown A, Sweeting H, Logan $G$, et al. Prison staff and prisoner views on a prison smoking ban: evidence from the Tobacco In Prisons study. Nicotine and Tobacco Research (Early online publication doi:101093/ntr/nty092) 2018

4. Sweeting H, Semple S, Demou E, et al. Predictors of opinions on prison smoking bans: Analyses of survey data from Scottish staff and prisoners. Tobacco Induced Diseases 2019;17:47.

5. Woodall J, Tattersfield A. Perspectives on implementing smoke-free prison policies in England and Wales. Health Promotion International 2018;23:1066-73.

6. Hefler M, Hopkins R, Thomas D. Successes and unintended consequences of the Northern Territory's smoke-free prisons policy: results from a process evaluation. Public Health Research \& Practice 2016;26:e2621619.

7. Kennedy SM, Davis SP, Thorne SL. Smoke-Free Policies in U.S. Prisons and Jails: A Review of the Literature. Nicotine \& Tobacco Research 2015;17:629-35.

8. Robinson A, Sweeting H, Hunt K. UK news media representations of smoking, smoking policies and tobacco bans in prisons. Tobacco Control 2018;27:622-30.

9. Scottish Prison Service. Scottish Prison Service Annual Report \& Accounts 2018-2019. Edinburgh: Scottish Prison Service, 2019.

10. Semple S, Dobson $\mathrm{R}$, Sweeting $\mathrm{H}$, et al. The impact of implementation of a national smoke-free prisons policy on indoor air quality: results from the Tobacco in Prisons study. Tobacco Control Published Online First: 07 May 2019 doi: 101136/tobaccocontrol-2018-054895 2019 
TABLE 1: Agreement with opinion items among prisoners and staff: before a Scottish prisons smoking ban was announced (Phase 1); following the announcement (Phase 2); and following implementation of the ban (Phase 3) - numbers and percentages, and any between-phase differences with $p$ value $<0.01$

\begin{tabular}{|c|c|c|c|c|c|c|c|c|}
\hline & \multicolumn{4}{|c|}{ PRISONERS } & \multicolumn{4}{|c|}{ STAFF } \\
\hline & Phase 1 & Phase 2 & Phase 3 & Sig diffs* & Phase 1 & Phase 2 & Phase & Sig diffs* \\
\hline & (N) $\%$ & (N) $\%$ & (N) $\%$ & & (N) $\%$ & (N) $\%$ & $(\mathrm{~N})$ & \\
\hline
\end{tabular}

\section{RETURNED QUESTIONNAIRES}

$\underline{(1,959) 25.9} \quad(1,485) 18.1$

$(1,271) 26.6 \quad(1.494) 31.4$

(757) 16.1

Prison smoking bans (agree / strongly agree)

Prison smoking bans are a good idea

Prison smoking bans cause a lot of trouble

Prison smoking bans help prisoners stop smoking longterm

Prison smoking bans are hard to enforce

Most staff want prison smoking bans

Prison smoking bans are OK if enough stop-smoking support is available

Prison smoking bans are OK if prisoners allowed e-cigs

\section{Smoking restrictions in Scottish prisons}

In favour of (hypothetical / impending / actual) increased smoking restrictions in Scottish prisons

\section{Prisoners' access to e-cigarettes (agree)}

Should e-cigs be available to prisoners to buy from the canteen?

Should e-cigs be given to prisoners temporarily to help with tobacco withdrawal when admitted to prison? Should e-cigs be available to help prisoners stop smoking / manage without tobacco?

\begin{tabular}{|c|c|c|c|c|c|c|c|c|c|c|c|c|c|}
\hline (542) & 22.4 & (477) & 25.3 & (502) & 35.4 & $1<3,2<3$ & (937) & 73.9 & (853) & 68.6 & (554) & 86.4 & $1<3,2<3$ \\
\hline$(1,954)$ & 81.2 & $(1,502)$ & 79.9 & (817) & 58.2 & $1>3,2>3$ & (737) & 58.1 & (859) & 69.0 & (212) & 33.0 & $1>3,1<2,2>3$ \\
\hline (495) & 20.7 & (433) & 23.3 & $(342)$ & 24.4 & - & (640) & 50.4 & (480) & 38.6 & (269) & 41.8 & $1>3,1>2$ \\
\hline$(1,545)$ & 64.5 & $(1,096)$ & 58.6 & $(500)$ & 35.7 & $1>3,1>2,2>3$ & (780) & 61.6 & (749) & 60.4 & (228) & 35.5 & $1>3,2>3$ \\
\hline (782) & 32.7 & (778) & 41.8 & $(625)$ & 44.6 & $1<3,1<2$ & (788) & 62.1 & (730) & 58.5 & (471) & 73.5 & $1<3,2<3$ \\
\hline (877) & 36.6 & (794) & 42.6 & $(615)$ & 43.9 & $1<3,1<2$ & (849) & 67.1 & (840) & 67.9 & (484) & 75.4 & $1<3,2<3$ \\
\hline$(1,158)$ & 48.4 & (837) & 44.9 & (678) & 48.5 & - & (451) & 35.5 & (536) & 43.0 & (377) & 58.5 & $1<3,1<2,2<3$ \\
\hline (564) & 23.5 & (467) & 25.0 & (384) & 27.3 & - & $(1,004)$ & 79.0 & (871) & 69.9 & (524) & 83.7 & $1<3,1>2,2<3$ \\
\hline \multicolumn{7}{|c|}{ Not asked of prisoners in all phases } & (673) & 53.2 & (908) & 72.9 & (510) & 79.2 & $1<3,1<2,2<3$ \\
\hline \multicolumn{7}{|c|}{ Not asked of prisoners in all phases } & (593) & 47.1 & (836) & 67.6 & (438) & 67.9 & $1<3,1<2$ \\
\hline$(2,125)$ & 90.1 & $(1,673)$ & 90.2 & $(1,248)$ & 88.8 & - & (684) & 54.1 & (926) & 74.9 & $(470)$ & 73.0 & $1<3,1<2$ \\
\hline
\end{tabular}

* $p<0.01$ due to large numbers of tests/comparisons; analyses via logistic regressions adjusting for socio-demographic variables associated ( $\mathrm{p}<0.01$ ) with both phase and opinions (For prisoners: age (but not sex, convicted/remand status, self-rated health or ever-smoker); for prison staff: sex and operational/non-operational role (but not age, self-rated health or ever smoker)). Note unadjusted results almost identical. 